\title{
Research on Energy-Saving Technology of Ocean-Going Ship Electrical Equipment
}

\author{
Xinyu Zhu* \\ School of Wuhan University of Technology, Wuhan, China
}

\begin{abstract}
In recent years, my country's high-tech technology has shown an unstoppable development trend, which has promoted the application of electrical equipment in the domestic shipbuilding industry. Energy conservation and environmental protection have gradually become the theme of the times. Ships need to pay attention to the application of energy-saving technology when applying electrical equipment to ensure that ships can play a practical role in green and environmental protection. This article focuses on the problem that the power consumption of marine auxiliary machinery greatly affects the endurance, and elaborates the energy-saving technology of marine auxiliary electrical equipment in detail, and analyses the energy-saving effect it can bring, and finally the application prospects of the marine auxiliary energy-saving technology the outlook was carried out.
\end{abstract}

Keywords: Marine auxiliary machinery, energy saving, energy management.

\section{Introduction}

Compared with the land power grid, the ship power grid is an independent small-capacity system, and the ship auxiliary machinery is one of the main power loads of the ship power grid. Due to the limited energy carried by ships, excessive power consumption of auxiliary engines will inevitably occupy the energy share required by the ship's main propulsion equipment, which will affect the increase of ship's navigation endurance, resulting in increased shipping costs, which is not in line with the energy-saving reduction in the national energy policy. Platoon requirements [1]. Therefore, the use of energy-saving technologies to reduce the energy consumption of auxiliary engines is an effective way to increase the endurance of ships and reduce operating costs. It is of great significance in today's increasingly tense world energy situation.

As ship electrical equipment is an important component of ship power grid, and the energy consumption of ship electrical equipment is relatively high, it causes huge consumption of ship energy and brings greater pressure to the timely supply of ship energy. Therefore, once a ship on a long journey has limited energy supply, its electrical equipment may run slowly, which directly affects the normal navigation of the ship. In the context of

\footnotetext{
* Corresponding author email:286007@whut.edu.cn
} 
the era of energy conservation and environmental protection, research on energy-saving technologies for ship electrical equipment has increasingly become a research focus.

\section{Necessity of energy-saving technology for marine electrical equipment}

The use efficiency of electrical equipment on ships is directly related to the effect of energy-saving technology. As part of the electrical equipment continues to operate during the course of the ship, and the inherent energy of the ship is constantly being consumed, it can be gradually realized by means of improving the efficiency of the use of such electrical equipment. The effect of energy saving and environmental protection of electrical equipment. For different electrical equipment on ships, it is necessary to select appropriate energy-saving technologies to achieve the best energy-saving effects for various electrical equipment. Since changes in the external environment have a greater impact on the operation of electrical equipment on ships, changes in the environment often change the load voltage of electrical equipment on ships and increase the energy consumption of electrical equipment on ships [2]. At the same time, when the actual power of the ship's electrical equipment exceeds the standard power due to environmental changes, the current used by the electrical equipment will increase and the independent power grid used by the electrical equipment will be damaged. In addition, the high energy consumption of marine electrical equipment caused by environmental impacts violates the theme of energy conservation and environmental protection and seriously affects the sustainable and healthy development of the marine industry. Therefore, it is extremely urgent to be familiar with the operating conditions of the energy-saving technology of marine electrical equipment and to study the specific application scheme of the energy-saving technology of marine electrical equipment.

\section{Motor energy-saving technology}

According to the different electrical systems of the ship's power grid, the current ship auxiliary motors include DC motors and AC asynchronous motors. As the ship's navigation conditions change, the load of the auxiliary machinery or the voltage of the power grid will change, which will cause the output power of the auxiliary machinery motor to deviate from the rated power, and the phenomenon of "big horse-drawn trolley" appears. At this time, the motor efficiency is drastically reduced, and the electric energy the loss is greatly increased. In addition, for AC asynchronous motors, the power factor is generally about 0.8 . When the load of the auxiliary machine is reduced a lot (such as when it is close to no load), the power factor is also greatly reduced, resulting in an increase in the reactive component of the grid current and network loss [3]. Increase; and because of the brushes of the DC motor, the mechanical commutation during operation will cause electric sparks, and the brushes need to be cleaned or replaced regularly, and the motor maintenance workload is relatively large.

The permanent magnet synchronous motor, which has developed rapidly in recent years, provides an effective technical way to solve the above-mentioned problems of the marine auxiliary motor and improve the energy efficiency of the motor [4]. The rotor of the permanent magnet synchronous motor is made of permanent magnet material. There is no induced current on the rotor side, and there is no rotor hysteresis loss and eddy current loss, which improves the efficiency of the motor; because there is no need for rotor excitation, the power factor of the motor can be close to 1 , which reduces the stator The current further improves the efficiency of the motor, and at the same time improves the quality of the 
power grid and reduces the network loss; the efficiency is high in the full power range, even if the load is reduced to $25 \%$ of the rated load, the efficiency of the permanent magnet motor can still reach more than $90 \%$. Fans and pumps are typical square torque type loads. The relationship between flow $\mathrm{q}$, head $\mathrm{H}$, power $\mathrm{p}$ and speed $\mathrm{n}$ are shown in equation (1).

$$
\frac{q_{1}}{q_{2}}=\frac{n_{1}}{n_{2}}, \frac{H_{1}}{H_{2}}=\left(\frac{n_{1}}{n_{2}}\right)^{2}, \frac{P_{1}}{P_{2}}=\left(\frac{n_{1}}{n_{2}}\right)^{3}
$$

It can be seen from formula (1) that the flow of the fan and pump is proportional to the motor speed, the electric power consumed is proportional to the third power of the motor speed, and the electric power is proportional to the product of the flow and the head. Therefore, when the pipeline characteristics remain unchanged, reducing the speed by reducing the flow rate can achieve significant energy-saving effects. Figure 1 shows the comparative analysis of fan and pump using speed regulation method to reduce flow and interception method to reduce flow. In Figure 1, $\mathrm{M}$ is the operating point when the valve is fully open, corresponding to the speed n, flow $q_{V M}$, head $H_{M}$ and pipeline characteristic curve I. When the flow is reduced by the interception method, because the outlet valve is closed, the pipeline resistance increases, and the pipeline characteristic curve changes from I to I', but the motor speed $\mathrm{n}$ does not change at this time, and the auxiliary machine work characteristic curve does not change, so The operating point moves from $\mathrm{M}$ to $\mathrm{A}$ along the original operating characteristic curve, which corresponds to the speed n, the flow rate $q_{V A}$, the head $H_{A}$ and the pipeline characteristic curve I'.

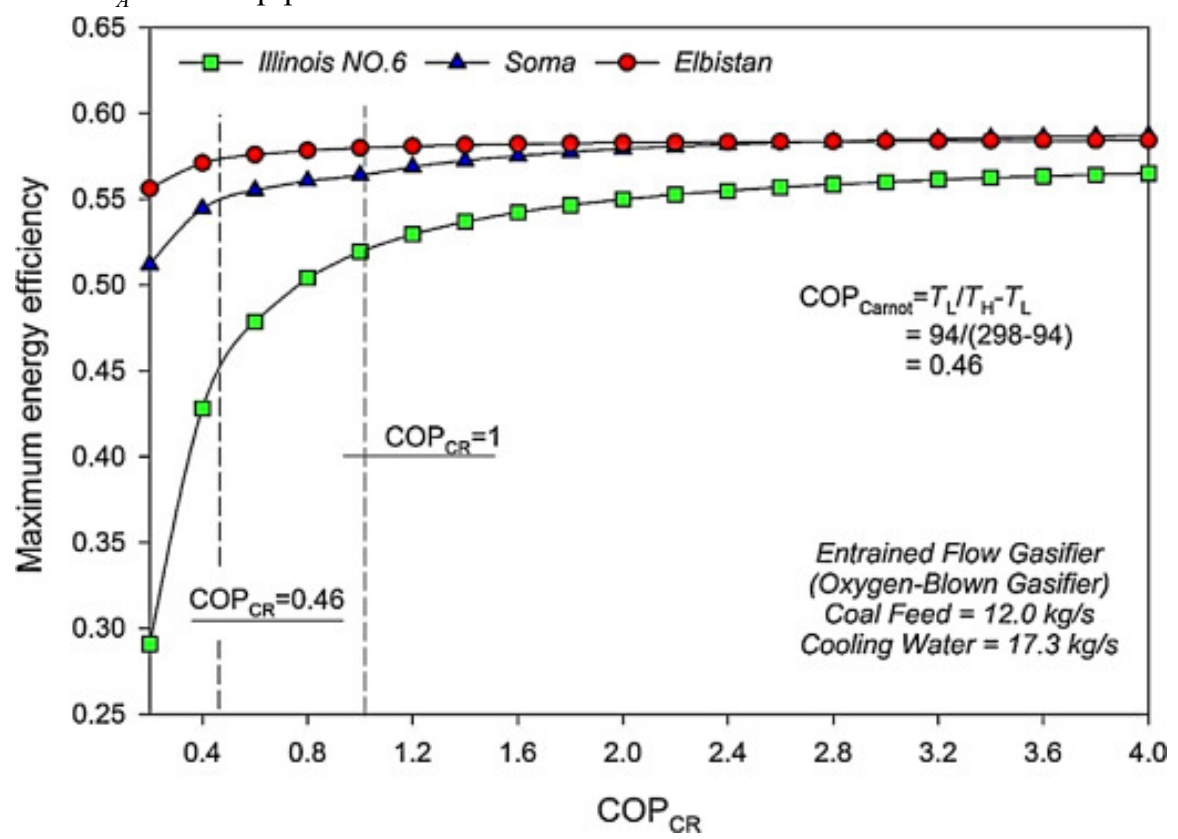

Figure 1. Comparison of speed reduction method to reduce flow and interception method to reduce flow

The frequency conversion speed control device is used to control the operating speed of the ship's auxiliary machinery. According to the actual flow demand of the system, the auxiliary machine's speed is dynamically adjusted in real time to control the flow output. The energy saving effect is very obvious. It should be noted that, as shown in Equation (1) 
and Figure 1, when the speed drops, the head of the fan and pump decreases with the speed of the speed. Therefore, when adjusting speed and saving energy, it is necessary to consider whether the head meets the system requirements. Therefore, the speed adjustment range cannot be too large, generally within the range of $70 \%$ to $100 \%$ of the rated speed.

\section{Energy saving of food cold storage system for ocean-going ships}

According to the second law of thermodynamics, the reverse Carnot cycle has the highest cooling efficiency. There are various irreversible effective energy losses in the actual refrigeration cycle of food cold storage [5]. The magnitude of the effective energy loss characterizes the extent to which the actual refrigeration cycle deviates from the ideal reverse Carnot cycle, and thus points out the way to save energy in refrigeration. Most food cold storages use piston reciprocating refrigeration compressor units with relatively high adiabatic efficiency (see Figure 2).

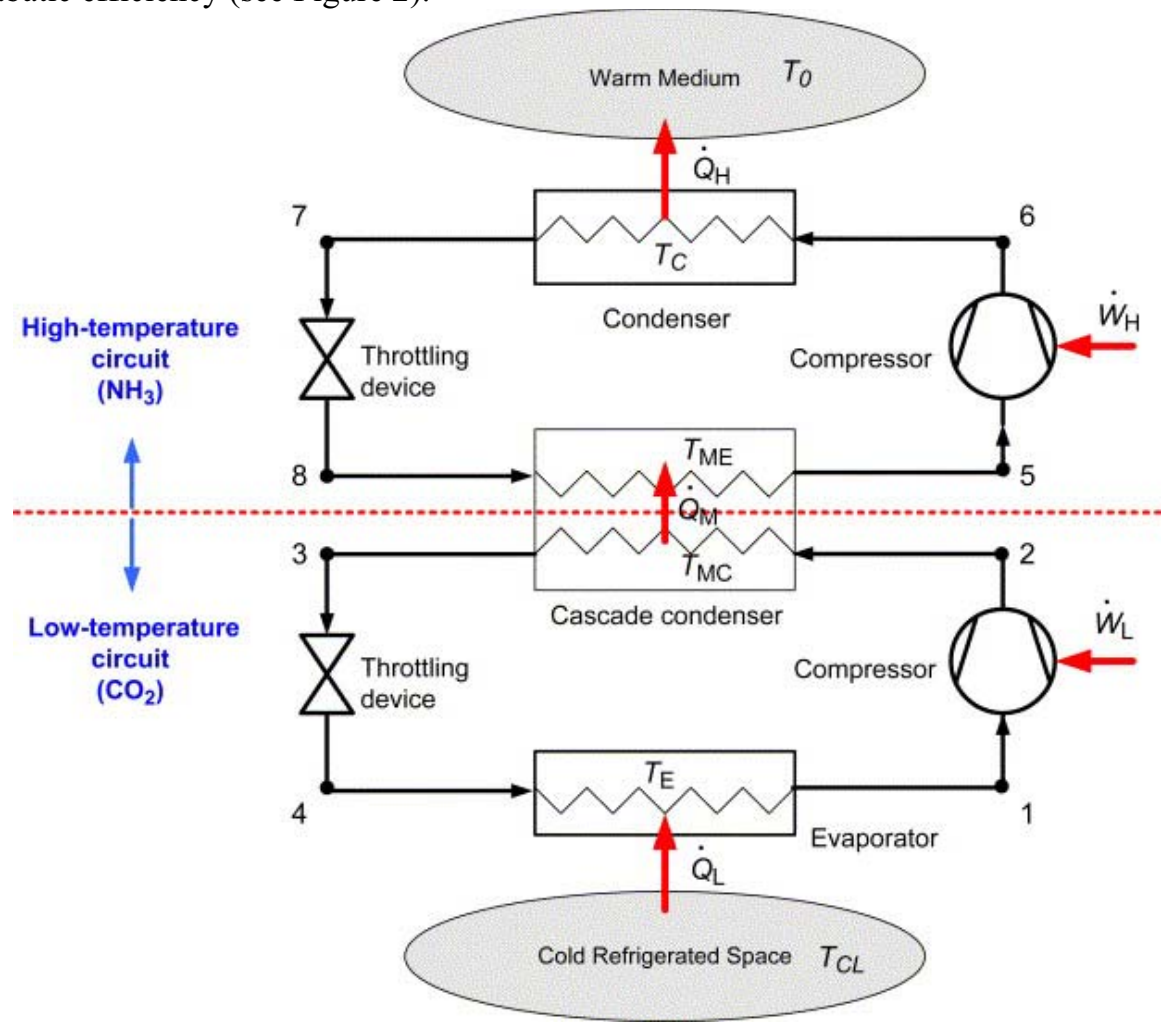

Figure 2. Diagram of the refrigeration system of a ship's food refrigeration device

The actual compression process of the compressor is an irreversible process, which deviates from the equal adiabatic compression process. Therefore, while the compression process increases, it also produces an increase. In the refrigeration cycle, this part cannot be used, but can only be transferred to the environment through the condenser. Therefore, the effective energy loss during the suppression process is

$$
\Delta e_{\text {comp }}=\omega+\left(e_{1}+e_{2}\right)=T_{a}\left(s_{2}-s_{1}\right)
$$


In the formula, $e_{1}+e_{2}$ represents the difference, that is, the compression work consumed in the irreversible compression process; $\omega$ represents the adiabatic pressure adiabatic motion. The effective energy loss in the throttling process is:

$$
\Delta e_{\text {exp }}=e_{1}-e_{2}+\int_{1}^{2}\left(1-\frac{T_{0}}{T}\right) d p=e^{3}-e^{4}
$$

In the formula, $e_{1}, e_{2}$ represents the refrigerant at the inlet of the throttle valve; $\int_{1}^{2}\left(1-\frac{T_{0}}{T}\right) d p$ represents the effective energy of the refrigerant to absorb or release heat. In the condenser and the evaporator, the hot and cold fluids transfer heat under the temperature difference, so the effective energy loss is:

$$
\Delta e=d Q \circ \frac{T_{1}-T_{2}}{T_{1} \cdot T_{2}} T_{a}
$$

In the formula, $T_{1}, T_{2}$ represents the temperature of the hot and cold fluid; $T_{a}$ represents the environmental temperature difference.

\subsection{Energy saving in the refrigeration cycle}

When a tall ship sails in tropical shipping areas or hot seasons, the food cold storage has a large heat load. At this time, the input frequency of the asynchronous motor can be changed through the frequency converter to increase the compressor speed, output power and refrigerant flow to increase the cooling capacity, so that it can meet the needs of the cold storage thermal load. When the compressor is working at a higher speed, although its total power consumption will increase, this not only exchanges the balance of heat exchange, but also ensures that the storage temperature is maintained at the necessary low temperature, and the amount of heat exchange between the refrigerant gas and the cylinder The relative reduction in suction and discharge resistance increases the compressor's adiabatic efficiency, reduces the relative unit compression work, and increases the effective energy efficiency accordingly [6]. When the ship sails into low temperature waters or sails at night, the heat load of the refrigeration system decreases. For example, when sailing from a sea area with an ambient temperature of $40^{\circ} \mathrm{C}$ to a sea area of $25^{\circ} \mathrm{C}$, adjust the compressor speed to $75 \%$ of the rated speed. This not only ensures that the cooling capacity matches the thermal load, but also reduces the compressor shaft power by about $25 \%$, and It can reduce the mechanical friction loss of the refrigeration device and improve the total effective energy efficiency.

\subsection{Energy saving in the operation and management of refrigeration units}

Under certain evaporating temperature and compressor suction conditions, reducing the condensing temperature and pressure as much as possible is one of the most effective ways to save energy in the refrigeration system. Minimizing the heat transfer temperature difference between the high-temperature refrigerant vapor and the cooling water is the most effective measure to reduce the condensation pressure and temperature in the cold storage operation [7]. That is, the scale and dirt on the water side surface of the condenser should 
be removed regularly to reduce the heat transfer resistance; the non-condensable gas in the system should be removed, the excessive refrigerant in the system should be released, and the condensing pressure regulating valve should be in good working condition. Experiments show that when the scale on the water side of the condenser tube bundle is 1.5 $\mathrm{mm}$, the condensing temperature will increase by $2.8^{\circ} \mathrm{C}$, and the power consumption of the motor will increase by $9.7 \%$; when the partial pressure of the non-condensable gas in the refrigeration system reaches 0 At $196 \mathrm{M} \mathrm{Pa}$, the compressor power consumption will increase by $18 \%$.

\subsection{Application of operation control energy-saving technology}

In the application of energy-saving technology for air-conditioning equipment operation control, variable-frequency speed-regulating fans and compressors can be selected. According to the distribution of people in the cabin, the temperature and humidity inside and outside the cabin, and the water temperature in the navigation area, it can meet the overall needs of the cabin personnel In the case of environmental requirements, automatically adjust the cooling or heating capacity to complete the economic and energysaving goals of air-conditioning equipment operation. Since air conditioners are the main energy-consuming electrical equipment of ships, their purpose is to meet the needs of personnel [8]. Therefore, it is necessary to adjust the operating power based on the frequency conversion performance of the air conditioner in time according to the changes in the cabin area personnel and the temperature in the cabin, thereby reducing the energy consumption of the air conditioning equipment . For the application of energy-saving technology for ventilation unit operation control, it is necessary to combine information such as navigation conditions, cabin atmosphere temperature and humidity, cabin atmospheric content and air pressure, and select variable frequency speed regulation energy-saving technology to adjust the air supply volume of the ventilator, that is, according to the atmospheric environment and navigation conditions, etc. In specific circumstances, the automatic adjustment of the air supply volume of the fan speed is used to achieve the effect of energy saving.

\section{Conclusion}

In recent years, ship technology has been further reformed, vigorously promoting the gradual development of my country's ship auxiliary electrical equipment in the direction of automation, and the technical level of drone cabins and remote control is also increasing. As my country's energy shortage becomes more and more serious, the application of energy-saving technology in the electrical equipment of marine auxiliary machinery is also becoming more widespread, and it is highly valued by the shipping industry and manufacturing industry. Through the application of energy-saving electrical equipment on ships, the operational capacity and efficiency of ships can be improved, energy utilization can be increased, energy waste can be greatly avoided, pollution emissions can be reduced, and the marine environment and atmospheric environment can be improved. my country should strengthen the research of energy-saving ships, and strive to meet the requirements of green standards for safety, energy saving, environmental protection and low emission, so that energy saving and green become the core competitiveness of the shipbuilding industry.

\section{References}

1. Kim, K. I., \& Lee, K. M. Dynamic programming-based vessel speed adjustment for 
energy saving and emission reduction. Energies, 11(5) (2018) 1273-1279.

2. Wang, K., Yan, X., Yuan, Y., \& Tang, D. Optimizing ship energy efficiency: Application of particle swarm optimization algorithm. Proceedings of the Institution of Mechanical Engineers, Part M: Journal of Engineering for the Maritime Environment, 232(4) (2018) 379-391.

3. Yuan, Y., Li, Z., Malekian, R., \& Yan, X. Analysis of the operational ship energy efficiency considering navigation environmental impacts. Journal of Marine Engineering \& Technology, 16(3) (2017) 150-159.

4. Fan, A., Yan, X., Yin, Q., Sun, X., \& Zhang, D. Clustering of the inland waterway navigational environment and its effects on ship energy consumption. Proceedings of the Institution of Mechanical Engineers, Part M: Journal of Engineering for the Maritime Environment, 231(1) (2017) 57-69.

5. Kang, Y. M., \& Oh, J. S. Development of Power Energy Management System for Ships including Energy Saving of Separated Load Systems. Journal of the Korea Institute of Information and Communication Engineering, 22(1) (2018) 131-139.

6. Schuiling, B., \& van Terwisga, T. Hydrodynamic working principles of Energy Saving Devices in ship propulsion systems. International Shipbuilding Progress, 63(4) (2017) 255-290.

7. Orosa, J. A., Costa, Á. M., \& Pérez, J. A. A new modelling procedure of the engine room ventilation system for work risk prevention and energy saving. Proceedings of the Institution of Mechanical Engineers, Part M: Journal of Engineering for the Maritime Environment, 231(4) (2017) 863-870.

8. Hasselaar, T. W., \& Xing-Kaeding, Y. Evaluation of an energy saving device via validation speed/power trials and full scale CFD investigation. International Shipbuilding Progress, 63(4) (2017) 169-195. 